\title{
Disentangling the Threads: Analysing Synchronous Online Discussions
}

\author{
Deirdre Grogan \\ School of Education, Faculty of Humanities and Social Sciences, University of Strathclyde, Glasgow, UK \\ Email: d.grogan@strath.ac.uk
}

Received 10 February 2015; accepted 8 March 2015; published 11 March 2015

Copyright (C) 2015 by author and Scientific Research Publishing Inc.

This work is licensed under the Creative Commons Attribution International License (CC BY).

http://creativecommons.org/licenses/by/4.0/

(c) (i) Open Access

\section{Abstract}

This paper investigates features of synchronous chat-communication within a postgraduate elearning programme that is rooted communities of enquiry (Lave \& Wenger, 1991). This project, funded by the Scottish Government, was to provide staff development for teachers throughout Scotland. The paper considers approaches to making sense of disparate threads of online chats between tutors and students and methodological issues in identifying the appropriate unit of analysis. The framework for analysis was derived from promotion of a community of enquiry perspective (Garrison, 2007; Garrison \& Vaughan, 2008) which emphasises the importance of the intersection of social, cognitive and teaching presence for achieving shared learning goals. A quantitative content analysis of transcripts from tutor led group chats was used to determine frequencies of teaching presence, social presence, and cognitive presence indicators. Results show that overall, $\mathbf{7 0 \%}$ of the contributions were coded as facilitating cognitive discourse. This finding builds on previous research by Ortiz-Rodriguez et al. (2005) which suggests that instructors can influence cognitive presence within synchronous chat. It is suggested that the community of learning enquiry has the potential to help identify critical points for encouraging cognitive presence within synchronous chats. In addition, the study has implications for the growing number of guidelines for the design of online learning environments, particularly in terms of the extent to which synchronous chats have potentially underestimated the value of synchronous learning environments in supporting deeper, critical thinking and shared reflection among learners.

\section{Keywords}

E-Learning, Synchronous Discussion Groups, Learning Communities Reflection

\section{Introduction}

As e-learning technology advances and becomes more reliable, user friendly and mobile, it increasingly impacts 
and shapes academic activities in higher education. The use of computer mediated communication has become a standard component in many university courses. There has been a rapid growth in the number of courses offered in a blended learning format in which some face-to-face time is replaced by online activities (Arabasz, Boggs, \& Baker, 2003). This is of general interest since student participation is a central issue in online education (Bento \& Schuster, 2003; Masters \& Oberprieler, 2004).

As institutions adopt e-learning, important questions have arisen-how can courses be designed to incorporate e-learning into their pedagogy successfully? What is the most effective combination of e-learning tools within blended learning programmes? What role do e-learning tools play in developing communities of inquiry among learners? What is the role of synchronous online chats in developing communities of inquiry? What are the most effective methods for analysing online learning discussions? The purpose of this article is to examine the role of synchronous chats in developing and sustaining a community of enquiry within a postgraduate teacher education programme of blended learning design. The study developed a detailed method for measuring the complex process of online student participation and aims to evaluate the effectiveness of on line learning to develop teachers' thinking, reflection and practice within their working environment.

\section{Review of Literature}

\subsection{Community of Inquiry Framework}

The CoI framework was originally developed to inform research into online learning (Garrison et al., 2000). Garrison (2007), addressing the issues from a "community of enquiry” perspective, highlights the importance of the intersection of social, cognitive and teaching presence for the purposes of achieving a common goal in developing community and meaningful learning. The CoI framework proposes that three intersecting presencessocial, cognitive and teaching - are central to educational experiences that have depth and meaning. The framework has increasingly permeated the field of online learning research. It has played a significant role in the evolution of methodological approaches for measuring each of the presences that are critical to a community of inquiry. The first of these presences that required accurate definition to support the research process was social presence.

Social presence is about learners sharing personal characteristics and developing trust with the community. Garrison and Vaughan (2008) emphasise the importance of students feeling "free to express themselves ... in a risk-free manner" and identify "open communication, group cohesion and affective/personal connections" as key categories in relation to social presence (p. 19). Others also focused on the issue of creating social presence and social interaction in an online environment Kreijns, Kirschner and Jochems (2003). Most interaction in online environments occurs around the educational objectives and social presence as such group identity and the sense of being part of a community may not develop. However, without the development of "personal and purposeful relationships" (Garrison \& Vaughan, 2008: p. 20) further discursive and collaborative engagement may not develop therefore course developers need to carefully plan the structure of the tasks, the nature of the facilitation provided and the provision of "non-learning for a" to stimulate productive social relationships (Kreijns et al., 2003).

Descriptions of cognitive presence have been the most robust. It was defined by the Practical Inquiry Model consisting of four phases-triggering event, exploration, integration and resolution/application (Garrison, Anderson, \& Archer, 2001). As such, cognitive presence is characteristic of shared meaning construction inherent in constructivist learning experiences. While a limited number of studies that have focused on cognitive presence using this model, it has been successful in measuring the developmental nature of the learning process across a range of learning contexts.

Teaching presence has been shown to be critical in the achievement of learning goals within a formal educational community of inquiry (Garrison \& Arbaugh, 2007). In common with the other presences, teaching presence is multi-dimensional and consists of three areas of responsibility-design, facilitation and direct instruction. Each of these is related to the co-ordination of social and cognitive processes in terms of the purposeful nature of the educational experience. To validate the structure of teaching presence, the literature advocates quantitative methodological techniques (Garrison \& Arbaugh, 2007).

This framework has been used in a large number of studies, as the basis for forming a methodology of analyzing transcripts. This exploratory, interpretivist approach certainly has shown to be fruitful, and forms the basis of the a priori codes and supplementary sub-codes that formed the basic units of analysis for examining the 
nature of synchronous online discussion in the present study.

Following Garrison, we focused on cognitive, social and teaching presence. Our research question derives from the assumption that learning is supported by learners' interactions with materials, peers and tutors.

\subsection{Chats as One Form of Synchronous Messaging}

An expanding body of literature was reviewed regarding the ways in which learners use synchronous communication tools (Cox et al., 2004; Hrastinski, 2008; Repman et al., 2005) and the different ways students respond online in synchronous and asynchronous learning platforms. Chats and other forms of synchronous messaging have been shown to be useful in building a sense of community and connection with other online learners (Cox et al., 2004; Curtis, 2004) and less useful in building cognitive presence or task accomplishment (Hrastinski, 2008). They can be useful in exploring the students' thinking, knowledge and reflection on key reading. Chats are useful also as a medium for giving and receiving advice on specific aspects of course work. Many researchers (Bober \& Dennen, 2001; Brown, 2000; Tuovinen, 2000) agree upon that social and informal communication between learners is an essential element of learning environments. When learners interact with each other, they learn from each other and share personal perspectives which help them to validate their own viewpoints while being exposed to and coming to understand other positions (Bober \& Dennen, 2001; Bowden \& Marton, 1998). Chats are also useful for providing a sense of being in a class and having a shared learning experience, thus perhaps helping students to feel more confident in their class performance and reducing the feeling of being distant from other learners (Wang \& Chen, 2007). Burnett (2003) investigated the role of the instructor and found that specific types of instructor behaviour could increase social interaction, focus the conversations on specific threads, and improve the intellectual level of the conversation. Asynchronous communication is thought to encourage more time on task, while synchronous communication appears to generate higher levels of social and community-building responses (Bober \& Dennen, 2001; Chou, 2000; Hines \& Pearl, 2004; Hrastinski, 2008).

The need for structure and direction in chat rooms was also noted by Ortiz-Rodriguez, Telg, Irani, Roberts, and Rhoades (2005), who examined student perceptions of quality in distance education. Based on student comments, Ortiz-Rodriguez et al. (2005) suggest that instructors can improve the cognitive presence of a chat by developing chat questions and keeping the conversation focused on the topic while encouraging diverse views. When evidence of the presence of critical thinking within synchronous chats has been found this has been identified as lower-order critical thinking (Penman \& Lai, 2003). Synchronous communication seems to encourage more soliciting of ideas, responses, and information as compared to statements posted only on a discussion board (Davidson-Shivers et al., 2001).

McAlister et al. (2004) increased the level of critical thinking by providing students with opening moves to challenge and deepen comments offered during chats. Using software that transformed chats into the appearance of threaded discussions with structured sentence openers resulted in more comments that c1allenged others' views, requested evidence for a given position, and built a higher level of collective knowledge. The use of software tools appears to improve the learning value of synchronous communication significantly (Loch \& McDonald, 2007). In addition, the use of small groups where issues could be resolved rather than large-group settings was also correlated with higher levels of critical thinking (Wickersham \& Dooley, 2006).

\section{Methodology}

Participants in this study were primary (elementary) grade teachers enrolled in a specialist course on early childhood pedagogy. The course, which was sponsored by the Scottish Government, was organised and run by a large university based in the central belt of Scotland. The course took place between April 2011 and March 2012 and comprised four modules delivered entirely in an online environment apart from a two-day, on-campus introduction at the beginning of the course and one recall day.

The course was designed to consist of four main modules. Students initially attended the campus for induction. The four modules which comprise the course were delivered entirely in an online environment, with the exception of a two day induction and one day on campus at the start of module three. Lectures, tasks and teacher forums were available on line on a weekly basis. Students were directed to online reading and had weekly synchronous online chats with tutors.

The two face-to-face induction days took the form of tutored sessions and workshops in which the teachers participated in demonstrations of how to use each element of the online learning including the synchronous and 
asynchronous communication tools. The workshops provide an opportunity for teachers to familiarise themselves with issues of course netiquette, understand the limitations of online interaction and develop their skills in technology use. Teachers had the opportunity to become familiar with the virtual learning system's operation including participating in chat rooms, searching for electronic course materials and posting to discussion forums. The face-to face on campus day at the end of the course provided opportunities to reflect collaboratively on course learning, communicate directly with tutors about course learning and technology issues and be introduced to course organisation structure relevant to the final course module.

Each of the four course module comprised of seven topics with a new topic introduced on a weekly basis. The pattern of engagement was that students would listen to an online lecture (in most units) and undertake recommended reading. The students then engaged in live online discussion within small groups of three to four individuals, arranged at a time convenient to the group. The thirty students were divided into 3 groups of 10 and each group was given a specific task to address and each week one of the group members summarised the discussion and posted it to the class discussion board. These groups of 10 were further divided into sub groups of $3 / 4$ who then joined other sub-groups once a week to engage in a live online discussion with the tutors. In module 4 the students worked in pairs (buddies) and then joined up with others to make two larger groups.

The weekly online chats with the tutor occurred when students had already engaged with the topic, reflected on it individually and participated in peer discussion that aimed to share and clarify understanding. The tutor-led discussions were therefore not necessarily exploring 'new' ideas but were providing the opportunity for elaborating meaning, representing thinking, indicating gaps in own understanding and explaining relevance relating to practice.

Weekly tutor-led synchronous chat discussions were subjected to content analysis that aimed to investigate the role of practical inquiry in developing cognitive, social and teaching presence. Transcripts of each chat were analysed in order to collect the data.

Content analysis goes below the surface-level measurement of online communications to examine the rich source of data students generate as they create meaning (Krippendorff, 2004). This approach allows text to be coded and summarized, and permits frequencies or percentages to be determined for comparison purposes and statistical testing (Strijbos, Martens, Prins, \& Jochems, 2004). The codes established for the analysis are given in Table 1.

The coding was initially set up in line with Garrison's (2007) model and the focus of contributions was used to calculate and categorise each online chat as shown in Table 1. On further reflection the specific categories had to be extended in order to create sub groups to aid both evaluation and analysis. It became clear that not only could tutor presence be sub divided into social, cognitive, teaching and other which allowed the researcher to critically evaluate the role of the tutor in promoting the chats or in enhancing the student's learning. Further categories had to be added to social discourse to group each element of the chats and specific categories were created. The tool was shaped in order to meet the needs of this specific course and to be used as a tool to evaluate the design of this new programme. Creating more specific sources allowed the new codes to analyse in finer detail the number of sources from each chat. The tool had advantages in term of the focus of contributions (Garrison, 2007) and to clearly highlight the number of tutor comments and student comments. The drawbacks of the tool could be categorising of the contributions and also in determining what is important in enhancing or extending the student learning.

Number of chats available for analysis

Technical problems, related mainly to module two, prevented all chats from being recorded resulting in 57 chats being available. A representative 11 chats were chosen for analysis, these being selected from the beginning, middle and end phases of the main group in each module. These chats related predominately to cognitive discourse and engagement.

Preparing the texts for analysis

Synchronous chats are by nature complex, with multiple interweaving threads and as such do not make for coherent text. As our purpose was to investigate the role that a contribution made in the development of discussion around a topic, the decision was taken to restructure the chat text, to draw all postings around one thread into a coherent "chunk". When reviewing coding, it would make it easier to find a contribution next to its relevant text, rather than a page and half further on. This was facilitated in chats where students followed the convention of naming the participant they were addressing the question or comment to, or who they were responding 
Table 1. Codes/categories for chats.

\begin{tabular}{cc}
\hline STUDENT & \\
\hline Focus of contribution & Sub groups \\
\hline
\end{tabular}

\section{A. Social presence (student)}

Social presence

\section{B. Cognitive presence (student)}

B1 Cognitive discourse/engagement

B2 Topic/content related

\section{Teaching presence (student)}

C1 Environment related

C2 Task and course related
1) Emotional support or comment

2) Greetings and byes

3) Social talk including work, family, weather

1) Acknowledge new learning (or need for it)

2) Agrees and gives explanation

3) Disagrees and gives explanation

4) Facts, examples, personal issues and opinions

5) Presence indicator

6) Question or comment seeking clarification

7) Question or comment that introduces a new dimension

8) Respond: clarify, extend, explain

- general

- to student

- to tutor

9) Summarises

1) Discuss topic in abstract/general way

2) Link topic to practice

3) Presence indicator

4) Reference to texts, resources etc.

5) Talk about changing practice (including barriers or need for practice to change)

1) Accessing materials

2) Acknowledge context e.g. self-correction

3) Presence indicator

4) Technical issues

1) Assignment related issues

2) Clarifying task for chat

3) Course issues and topics

4) Planning

5) Presence indicator

6) Reference to group task (i.e. pre-synchronous chat)

\section{TEACHER}

Focus of contribution

Sub groups

\section{A. Social presence (Teacher)}

Social presence

1) Social contribution

\section{B. Cognitive presence (Teacher)}

1) Ask direct question

Cognitive

2) Gives direction to discussion

3) Prompts clarification

4) Refocuses thinking in discussion

\section{Teaching presence (Teacher)}

Teaching

1) Responds to student question about topic

2) Elaborates or expands on topic

to. This exercise also identified some occasions where an individual made a point or asked a question, but that thread was not picked up and pursued. 
Unit of analysis

An individual post was taken as the unit of analysis. Some posts were very short for example "yes" and others were quite extensive, presenting a thought-out response to a particular question or point made. Therefore, clearly, not all posts are equal in terms of quality or quantity, but nonetheless play a role within the overall discussion. The main role in the learning conversation was used to clearly code each aspect of conversation. This is highlighted in Table 2.

Initial qualitative data analysis

The overview of the coding for all 11 synchronous chats is given in Table 2.

Table 2. Number of sources and references at each node across all eleven synchronous chats (each individual post coded as unit of analysis; some posts coded at more than one node).

\begin{tabular}{|c|c|c|c|}
\hline Focus of contribution & Sub groups & Sources & Refs \\
\hline \multirow{3}{*}{ Social presence } & Emotional support or comment & 2 & 2 \\
\hline & Greetings and byes & 11 & 103 \\
\hline & Social talk including work, family, weather. & 10 & 83 \\
\hline \multicolumn{4}{|l|}{ Cognitive presence } \\
\hline \multirow{12}{*}{$\begin{array}{l}\text { Cognitive } \\
\text { discourse/engagement }\end{array}$} & Acknowledge new learning (or need for it) & 7 & 12 \\
\hline & Agrees and gives explanation & 11 & 135 \\
\hline & Disagrees and gives explanation & 3 & 6 \\
\hline & Facts, examples, personal issues & 11 & 103 \\
\hline & Presence indicator & 11 & 159 \\
\hline & Question or comment seeking clarification & 7 & 51 \\
\hline & Question or comment that introduces a new dimension & 11 & 88 \\
\hline & Respond: clarify, extend, explain & 11 & $\underline{558}$ \\
\hline & - general & 10 & 70 \\
\hline & - to student & 11 & 190 \\
\hline & - to tutor & 11 & 298 \\
\hline & Summarises & 0 & 0 \\
\hline \multirow{5}{*}{ Topic/content related } & Discuss topic in abstract/general way & 11 & 392 \\
\hline & Link topic to practice & 11 & 396 \\
\hline & Presence indicator & 11 & 134 \\
\hline & Reference to texts, resources etc. & 9 & 32 \\
\hline & Talk about changing practice (including barriers or need for practice to change) & 4 & 18 \\
\hline
\end{tabular}

Teaching presence

Accessing materials

Environment related Acknowledge context e.g. self-correction

Presence indicator

Technical issues

Assignment related issue

Clarifying task for chat

Course issues and topics

Planning

Presence indicator

Reference to group task (i.e. pre-synchronous chat)

12

103

59

51

Task and course related

Social contribution

Ask direct question

Gives direction to discussion

Tutor presence Social

Prompts clarification

Refocuses thinking in discussion

Cognitive

Elaborates or expands on topic

Responds to student question about topic

Other

Environment issues (technical, self-correction, access resources)

Course or task issues

Direct question or comment on personal issues with individual student 


\section{Findings}

On the assumption that the 11 chats together are in some way representative of the broader experience, the figures in Table 2 (represented in Figure 1), do suggest that overall the discussion was very focused on the topics and the particular issues of the unit in question. There were social comments, comments about the technology and about other aspects of the course and assignments, which give a sense of being part of the bigger process but they do not dominate. To the researchers it appeared that those participating in the chats were open and comfortable with each other and this had developed through their other communications as well.

The section on "Teaching presence" includes all the tutor participation, as the tutor talk is a strong element of the teaching presence. Figure 2 and Figure 3 illustrate the student “talk” and tutor “talk” separately.

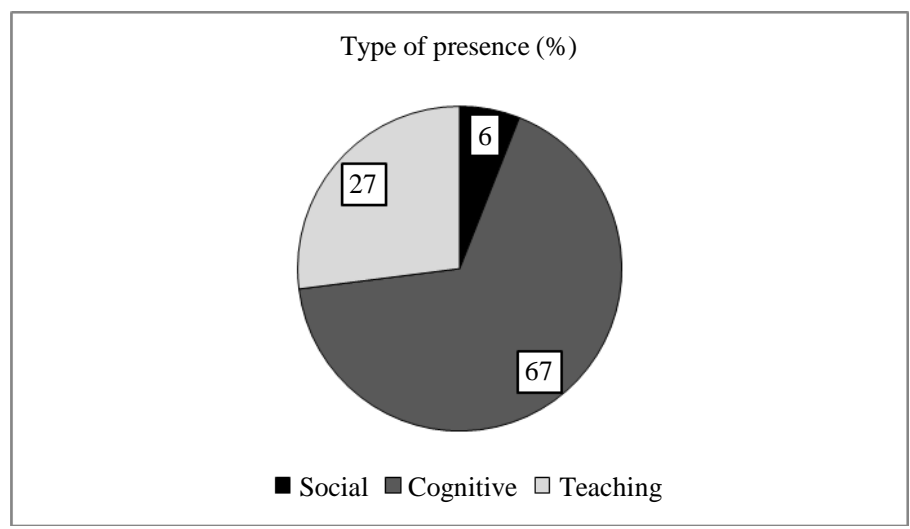

Figure 1. Overview of all 11 chats.

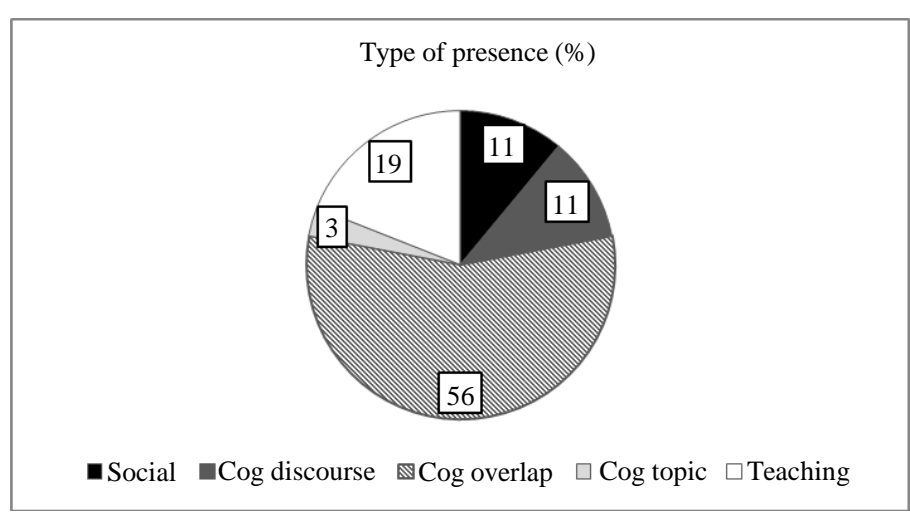

Figure 2. Overview of 11 chats-student “talk".

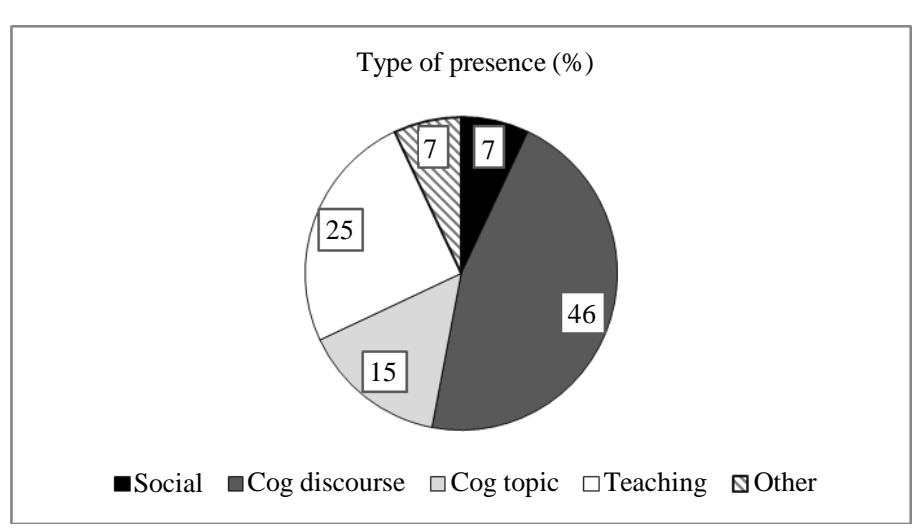

Figure 3. Overview of 11 chats-tutor "talk”. 
The separation of tutor and student talk emphasises the focus of the students on the substantive issues of the unit under discussion. The cognitive presence theme has been separated into its component parts—discourse and topic - discourse deals with the communicative epistemic function, for example, the types of statements made, agreeing, questioning, responding as shown in Figure 3. Topic refers to the way in which the topic was being addressed-in a general, abstract way, in relation to practice, and where the student posts referred to source materials to explain, substantiate or illuminate the theme. There was evidence that social presence among members of the learning community increased topic discourse and facilitated the critical thinking. There was evidence of support and encouragement exchanged between students, as well as willingness to critically evaluate the work of others with constructive comments.

A significant number of student posts categorised within the cognitive presence area were double-coded according to the role the posting played in the discussion and how it related to the topic - was it broad, general, theoretical, or were they talking about how this knowledge was used in practice or influenced their practice. The double coding is highlighted by the label "cognitive overlap". Overall, $70 \%$ of the contributions were coded as being part of the cognitive discourse. Notably some posts provided good general answers but did not always directly address discussion topics and assertions were not always supported by evidence.

For the tutor "talk" postings that elaborated on the topic or responded specifically to a question about the topic from a student were coded as topic related; otherwise their contributions were coded according to the function of the posting. This illustrates the point that tutors were more focused on questioning, direction and seeking clarification than further development of the topic. While tutors had an important facilitating role to play in topic discussions they displayed a common tendency to avoid becoming the centre of all discussions.

Different style of synchronous discussions

The chats were different in style. This is illustrated from examples from three discussions from Module 1.

Module 1 Tutor-Group A chat 1 (73 minutes)

This chat had 9 out of 10 student participants. The topics were introduced by the tutor with clear questions. The responses that followed were multi-threaded and included examples of interweaving-with three or four threads (in one case 5) interweaving. Postings are short, though joined together cover a lot of ground. 10 topics identified.

Module 1 Tutor-Group B chat 2 (73 minutes)

This chat had 9 out of 10 student participants. Most threads were initiated by tutor questions. Responses were multi-threaded. Given the multiple threads that emerged, some of them were only mentioned for a few posts and fairly superficially. In this chat there was a lot of dropping in and out of the chat because of people being cut off, frozen out, and lost connections. 7 topics identified.

Module 1 Tutor-Group C chat 3 (70 minutes)

This chat had 7 out of 8 participants. Topics were tutor led; students posted fairly long thought out responses with much less interweaving than other two groups for module 1 . They talked less to each other-they seemed more focused on responding to the tutor's questions. Two of the topics produced two threads. In this chat there was a lot of emphasis on examples of what they do that meets the principles put forward in the various theoretical perspective (5 or 6 topics). Eacg individual post is shown in Table 3 and Table 4.

It appears that in the first example, the students spent a lot of time responding to and communicating with each other, in the second example they communicate both with the tutor and other students and in the third example they spend most of the time communicating with the tutor.

Analysis

This kind of analysis provides a description of what was happening in the chats, based on important factors identified in the literature. It provides an opportunity for tutors to reflect on structure of the group chats and consider the extent to which non-learning focused strands of conversation can impact on cognitive discourse. Without the development of both personal and purposeful conversation the shape of conversational interweaving between students required for collaboration may be impacted. This is documented on Figure 4.

\section{Discussion}

Some researchers have expressed concern about the learning outcomes for e-learners, but a large scale review of comparative studies reveals no significant difference in learning outcomes between traditional and e-learning modes of delivery (Russell, 2001). 
Table 3. Different styles—3 chats (number of individual posts coded in each theme).

\begin{tabular}{cccccccc}
\hline & Student "talk" & & \multicolumn{5}{c}{ Tutor "talk" } \\
& Ex 1 & Ex 2 & Ex 3 & Ex 1 & Ex 2 & Ex 3 \\
Social & 18 & 16 & 13 & Social & 2 & 1 & 4 \\
Cognitive & & & & Cognitive & & & \\
Discourse & 258 & 212 & 68 & Discourse & 18 & 39 & 16 \\
Topic & 212 & 197 & 60 & Topic & 5 & 6 & 0 \\
Teaching & 15 & 9 & 6 & Environment & 3 & 8 & 10 \\
Environment & 15 & 10 & 10 & Task/Course & 2 & 11 & 7 \\
Task/Course & & & & & & & \\
\hline
\end{tabular}

Table 4. Different styles - 3 chats; focus on sub theme of "responds" (number of individual posts coded at each theme).

\begin{tabular}{ccccc}
\hline & \multicolumn{2}{c}{ Cognitive Discourse- “responds” } & Ex 2 & Ex 3 \\
\hline General & Ex 1 & 14 & 23 & 5 \\
To another student & 57 & 42 & 37 \\
To the tutor & 17 & 45 & 37 \\
\hline
\end{tabular}

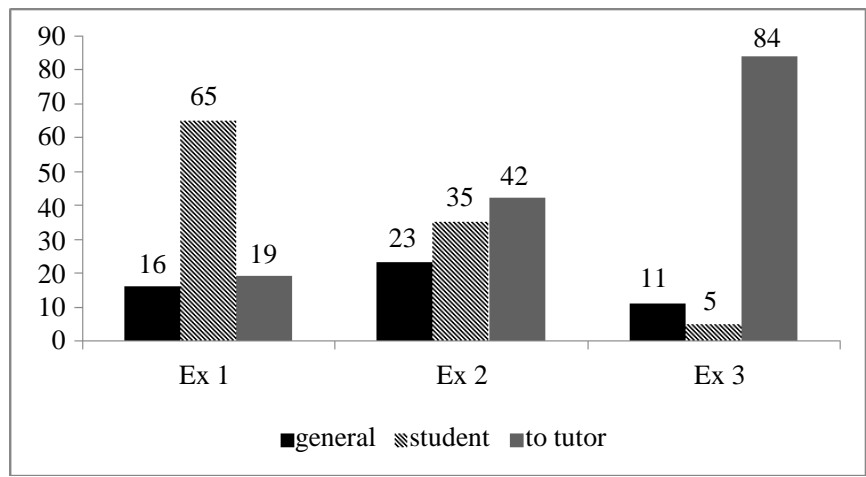

Figure 4. Different styles—3 chats; focus on sub theme of "responds" \%.

This article presents a methodology designed to analyse individual and group-level contributions that evidenced a developing community of enquiry in a teacher education course in a web based learning environment. Such an approach is consistent with methodological approaches that have emerged from the e-learning literature which contend that while investigation of individual-level processes of collaboration is necessary, it is not sufficient in describing the building of shared understanding, and that analyses must also be extended to the group level (Arvaja et al., 2007). Our study considers approaches to making sense of disparate threads of online chats, presents initial findings and raises questions about the future role of synchronous learning environments as a tool in shaping the development of e-learning courses.

Although the on-line discussions were designed for participants to "construct meaning through sustained communication” (Garrison, Anderson, \& Archer, 2001), rather than creating something entirely new, the major focus of each discussion centred around shared critical reflection on theories and perspectives relevant to the course. Our study found evidence of students describing, explaining, critiquing, evaluating, explicating, asking, challenging and responding, across the grouped chat room posts which is consistent with other research about the role of synchronous environments in learning (Cox, Carr, \& Hall, 2004; Davidson-Shivers, Muilenburg, \& Tanner, 2001; Hough, Smithey, \& Evertson, 2004). Our analysis provided examples of learner discourse indicative of divergent perspectives and convergence on some issues in which students integrated others viewpoints in their postings.

We found inter group differences in terms of the incidence of indicators of cognitive presence. Differences 
were evident both in terms of the number of discussion threads that were developed by each group and the extent to which students not only responded to a contribution made by a tutor and other students, but also incorporated into their responses relevant aspects of the comments made by other participants. The relatively high incidence of indicators of cognitive presence found in our study conflicts with findings that have suggested that synchronous computer mediated education is better suited for socialising, "rarely provides for productive discussion or participation" (Palloff \& Pratt, 1999: p. 3) and does not result in "academic" dialogue. Our findings also raise questions about the extent to which existing characteristics of individual student groups have contributed to observed differences in conversational styles given that most threads followed a common structure with chats initiated and led by tutor questions.

The students working in our web-based learning environment developed methods of interaction that were not adequately captured by the narrow focus of this study. The blended nature of the course design and specific provision of non-learning to support off-task communication within the induction arrangements included two social events attended by all course participants. In addition, more traditional modes of classroom delivery (including an initial series of face to face small and large group discussions) were specifically designed to clarify the professional development and academic objectives of the course as well as learner expectations as to the nature of critical discourse and their postings. Participants were also encouraged to form informal learning support networks to support their course of study. Such activities provided a basis for students getting to know each other, committing to social relationships, developing trust and belonging - characteristics recognised as supportive of building a shared sense of community (Northrup, 2001; Gunawardena, 1995; Cockburn \& Greenberg, 1993; Wegerif, 1998). We suggest that much our analysis took place at a time when the nature of social presence had shifted beyond simply establishing socio-emotional links and personal relationships and reached a level of cohesion (i.e. open and purposeful communication) and peer respect which facilitated common goal focused learning. Our findings are supportive of Swan (2003) who has suggested that the use of such cohesive indicators within the social presence category become less necessary as a clear classroom community is formed. However, the blended features of the course design serve to blur any interpretation of our data that seeks to draw a simple relationship between social and cognitive interaction in the synchronous online environment and collaborative learning within a community of enquiry. We suggest that positive learner outcomes and retention figures provide additional evidence to suggest that the synchronous environments served to maintain group cohesion and learner persistence in related asynchronous course learning tasks. In providing a shared intellectual focus and space to support other programmed asynchronous activity we contend that the synchronous discussion tools improved cognitive certainty about course issues across all members of the distributed learning group.

Our study was consistent with evidence that synchronous online chat sessions have medium specific limitations which include the technical skills of participants (Schwier \& Balbar, 2002). Participants reported that they experienced difficulty in exchanging ideas as quickly as with traditional face-to-face instruction. Our results are consistent with other research which has found that students who were inexperienced or encountered technical difficulties were not able to contribute as much to the conversations (Paulus \& Phipps, 2008).

\section{Conclusion}

In the context of evolving technology, the literature has highlighted the influences of the particular uses of tools and techniques within collaborative e-learning environments that distinguish the differences in learning outcomes (Moore, Dickson-Deane and Galyen, 2010). Our analysis illustrates the applicability of the methods used in investigating the mediating influence of text-based chat contexts on collaborative learning activity. Though the different groups typically worked at the same initial discussion tasks, the groups' and individuals' activity and meaning negotiations differed across the chat groups. There is some evidence that the nature of tutor presence can impact on the extent to which students engage in the shared exchanges of information, construct meaning through communication and connect ideas as opposed to more autonomous forms of discourse within the group context. In common with other studies (see Arvaja et al., 2007) that have investigated methods for studying collaboration in context, the chosen methodology offers a tool for detecting possible reasons for these differences. By revealing the influence of tutor presence on collaborative activities the tool has the potential to help identify critical points for encouraging cognitive presence within synchronous chats.

The study has implications for the growing number of guidelines for the design of online learning environments, particularly in terms of the extent to which they have potentially underestimated value of synchronous learning environments in supporting deeper, critical thinking and shared reflection among learners. Our evidence 
suggests that informed e-learning course designers do not need to limit the role of synchronous environments to task support exchanges such as planning work. While we have identified the characteristics of the synchronous on-line learning discussions, a more in-depth, larger scale study including an analysis of the inherent educational and transactional issues and group differences is required. Future study should explore the relationship between face-to-face off-task communication, the building of social relationships and group cohesion (Johnson \& Johnson, 1989, 1999) and how this might inform tutor support within synchronous chat discussions that seeks to provide incentives to collaborate. This would have the potential to further validate Garrison's community of inquiry model as a key theoretical framework for analysing the complexities of online learning.

\section{Acknowledgements}

I would like to acknowledge the contributions of Mary Welsh, Lecturer and Professor EffieMacLellan, University of Strathclyde.

\section{References}

Arabasz, P., Boggs, R., \& Baker, M. B. (2003). Highlights of E-Learning Support Practices. EDUCAUSE Research Bulletin, 2003, 11p.

Arvaja, M., Salovaara, H., Häkkinen, P., \& Järvelä, S. (2007). Combining Individual and Group-Level Perspectives for Studying Collaborative Knowledge Construction in Context. Learning and Instruction, 17, 448-459. http://dx.doi.org/10.1016/j.learninstruc.2007.04.003

Bento, R., \& Schuster, C. (2003). Participation: The Online Challenge. In A. Aggarwal (Ed.), Web-Based Education: Learning from Experience (pp. 156-164). Hershey, PA/London, UK: Idea Group Publishing. http://dx.doi.org/10.4018/978-1-59140-102-5.ch010

Bober, M. J., \& Dennen, V. P. (2001). Intersubjectivity: Facilitating Knowledge Construction in Online Environments. Educational Media International, 38, 241-250.

Bowden, J., \& Marton, F. (1998). The University of Learning: Beyond Quality and Competence in Higher Education. London: Kogan Page.

Brown, J. S. (2000). The Social Life of Information. Cambridge: Harvard Business School Press.

Cockburn, A., \& Greenberg, S. (1993). Making Contact: Getting the Group Communicating with Groupware. In Proceedings of the Conference on Organizational Computing Systems (COOCS '93) (pp. 31-41). Milpitas, CA: ACM Press.

Cox, G., Carr, T., \& Hall, M. (2004). Evaluating the Use of Synchronous Communication in Two Blended Courses. Journal of Computer Assisted Learning, 20, 183-193. http://dx.doi.org/10.1111/j.1365-2729.2004.00084.X

Davidson-Shivers, G., Muilenburg, L., \& Tanner, E. (2001). How Do Students Participate in Synchronous and Asynchronous Online Discussions? Journal of Educational Computing Research, 25, 351-366. http://dx.doi.org/10.2190/6DCH-BEN3-V7CF-QK47

Garrison, D. R., Anderson, T., \& Archer, W. (2001). Critical Thinking, Cognitive Presence, and Computer Conferencing in Distance Education. American Journal of Distance Education, 15, 7-23. http://dx.doi.org/10.1080/08923640109527071

Garrison, D. R. (2007). Online Community of Inquiry Review: Social, Cognitive and Teaching Presence Issues. Calgary: University of Calgary. http://people.ucalgary.ca/ nvaughan/coiissues.pdf

Garrison, D. R., Anderson, T., \& Archer, W. (2000). Critical Inquiry in a Text-Based Environment: Computer Conferencing in Higher Education. The Internet and Higher Education, 2, 87-105. http://dx.doi.org/10.1016/S1096-7516(00)00016-6

Garrison, D. R., \& Vaughan, N. D. (2008). Blended Learning in Higher Education: Framework, Principles, and Guidelines. San Francisco, CA: Jossey-Bass.

Gunawardena, C. N. (1995). Social Presence Theory and Implications for Interaction and Collaborative Learning in Computer Conferences. International Journal of Educational Telecommunications, 1, 147-166.

Hines, R. A., \& Pearl, C. E. (2004). Increasing Interaction in Web-Based Instruction: Using Synchronous Chats and Asynchronous Discussions. Rural Special Education Quarterly, 23, 33-36.

Hough, B., Smithey, M., \& Evertson, C. (2004). Using Computer-Mediated Communication to Create Virtual Communities of Practice for Intern Teachers. Journal of Technology and Teacher Education, 12, 361-386.

Hrastinski, S. (2008). Asynchronous \& Synchronous E-Learning. Educause Quarterly, 51-55.

Johnson, D. W., \& Johnson, R. T. (1989). Cooperation and Learning: Theory and Research. Edina, MN: Interaction Book Company. 
Johnson, D. W., \& Johnson, R. T. (1999). Learning Together and Alone: Cooperative, Competitive, and Individualistic Learning (5th ed.). Boston, MA: Allyn \& Bacon.

Kreijns, K., Kirschner, P., \& Jochems, W. (2003). Identifying the Pitfalls for Social Interaction in Computer-Supported Collaboration Learning Environments: A Review of Research. Computers in Human Behavior, 19, 335-353. http://dx.doi.org/10.1016/S0747-5632(02)00057-2

Lave, J., \& Wenger, E. (1991). Situated Learning: Legitimate Peripheral Participation. Cambridge: University of Cambridge Press.

López-Pérez, M. V., Pérez-López, M. C., \& Rodríguez-Ariza, L. (2011). Blended Learning in Higher Education: Students’ Perceptions and Their Relation to Outcomes. Computers \& Education, 56, 818-826. http://dx.doi.org/10.1016/j.compedu.2010.10.023

Masters, K., \& Oberprieler, G. (2004). Encouraging Equitable Online Participation through Curriculum Articulation. Computers and Education, 42, 319-332.

Northrup, P. (2001). A Framework for Designing Interactivity into Web-Based Instruction. Educational Technology, 41, 31-39.

Ortiz-Rodriguez, M., Telg, R., Irani, T., Roberts, T., \& Rhoades, E. (2005). College Students’ Perceptions of Quality in Distance Education: The Importance of Communications. Quarterly Review of Distance Education, 6, 97-105.

Pachler, N., \& Daly, C. (2011). Key Issues in e-Learning: Research and Practice. London: Continuum.

Palloff, R. M., \& Pratt, K. (1999). Building Learning Communities in Cyberspace: Effective Strategies for the Online Classroom. San Francisco, CA: Jossey-Bass.

Paulus, T., \& Phipps, G. (2008). Approaches to Case Analyses in Synchronous and Asynchronous Environments. Journal of Computer-Mediated Communication, 13, 459-484. http://dx.doi.org/10.1111/j.1083-6101.2008.00405.x

Penman, M., \& Lai, K. W. (2003). Synchronous Communication and Higher-Order Thinking in a Tertiary Course in Occupational Therapy. Journal of Interactive Learning Research, 14, 387-404.

Repman, J., Zinskie, C., \& Carlson, R. D. (2005). Effective Use of CMC Tools in Interactive Online Learning. Computers in the Schools, 22, 57-69. http://dx.doi.org/10.1300/J025v22n01_06

Schwier, R. A., \& Balbar, S. (2002). The Interplay of Content and Community in Synchronous and Asynchronous Communication: Virtual Communication in a Graduate Seminar. Canadian Journal of Learning and Technology, 28, 21-30.

Stricker, D., Weibel, D., \& Wissmath, B. (2011). Efficient Learning Using a Virtual Learning Environment in a University Class. Computers \& Education, 56, 495-504. http://dx.doi.org/10.1016/j.compedu.2010.09.012

Strijbos, J.-W., Martens, R. L., \& Jochems, W. M. G. (2004). Designing for Interaction: Six Steps to Designing ComputerSupported Group-Based Learning. Computers \& Education, 42, 403-424. http://dx.doi.org/10.1016/j.compedu.2003.10.004

Strijbos, J.-W., \& Stahl, G. (2007). Methodological Issues in Developing a Multi-Dimensional Coding Procedure for SmallGroup Chat Communication. Learning and Instruction, 17, 394-404. http://dx.doi.org/10.1016/j.learninstruc.2007.03.005

Swan, K. (2003). Developing Social Presence in Online Discussions. In S. Naidu (Ed.), Learning and Teaching with Technology: Principles and Practices (pp. 147-164). London: Kogan.

Tuovinen, J. E. (2000). Multimedia Distance Education Interactions. Educational Media International, 37, 16-24. http://dx.doi.org/10.1080/095239800361473

Wegerif, R. (1998). The Social Dimension of Asynchronous Learning Networks. Journal of Asynchronous Learning Networks, 2, 34-49.

Zemel, A., Xhafa, F., \& Cakir, M. (2007). What's in the Mix? Combining Coding and Conversation Analysis to Investigate Chat-Based Problem Solving. Learning and Instruction, 17, 405-415. http://dx.doi.org/10.1016/j.learninstruc.2007.03.006 